結語 肖述の力法で央塗で行つた絬果は大筋群と小

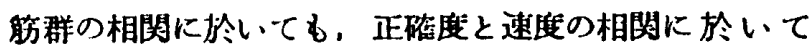
む，大体に於いてて，あ生语い相関係数は得られなかつ た。

\section{タイミンク澈作の研究 II}

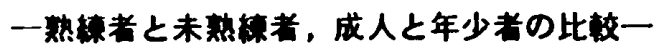

奈良女子大学

帒野 健次

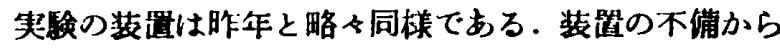
起る誤差が十分に考えられるので，こ〉では予俑的実駼 として，主として手つぐきと，結果から予想される傾向 を吟味するに止まることをお断りしておく。

\section{契験の言十画}

I 目的：移動梘䁖に対するタイミング反応に於ては， 鄱咟をした者（群 1）と練習をしない者（群 2)，と年少 者（样 3）間にどの様な特改的差翼があらわれるであろ

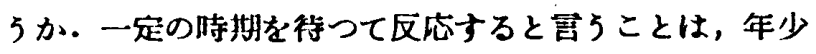
者には殊に困難なことではなかららか．又，タイミング がはをれれる言らことの条件として刺钱系列の効果の持 二役割は，末熟練者や年少者に於て大にあらわれるでは なからろか。

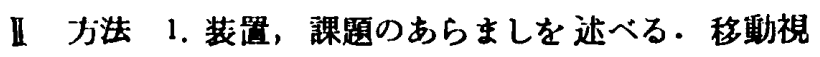

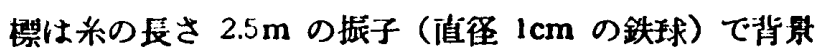
は黄色のカーテンを㖘り，暗公に於て前上的 $1 \mathrm{~m}$ のと ころに $100 \mathrm{~W}$ の照明を括く. 振子の軌道の觔半を衡立 で遮へいし，後半の部分を $1.5 \mathrm{~m}$ の距雏からの視野枠 を通して見る・枠の大きさはカーテンの面に於て楷 $1 \mathrm{~m}$ 絴 $2.5 \mathrm{~m}$. 铅淔線と振子の折返し点とのなす角度を $8^{\circ}$,

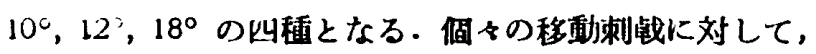

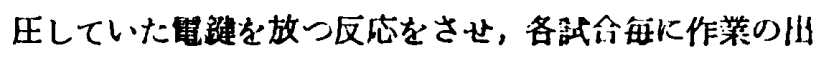
来ばえに刘して，完全な失敗を0自分としての㷅上を10 として，その間で評点させる。（但し年少者にはさせな

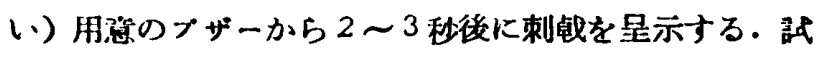

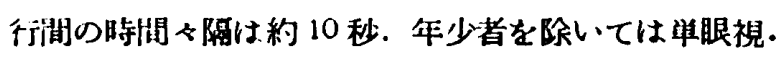

2. 手つがき，契験を二つに分け，第一车験は三系列 闹時に行い，第二実験は二梁列，他の同時に行つた。

第一然駼 移動視標に対与る各反応として，1 見元 たらすぐ $\left(R_{1}\right)$ 口止つたらすぐ $\left(R_{2}\right)$ 八止ると夙時

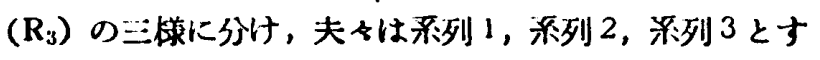
る. $\mathbf{R}_{1}$ と $\mathbf{R}_{2}$ は反応時間であり， $R_{3}$ のタイミング反応 との刘照の管味で入れた。剌械策件は $8^{\circ}, 10^{\circ}, 12^{\circ}$ の 三函を各6回シンダムにして訃18武行。

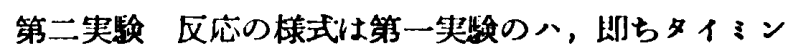

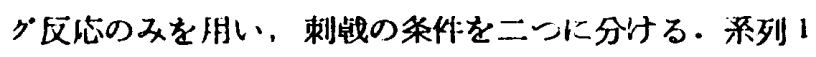

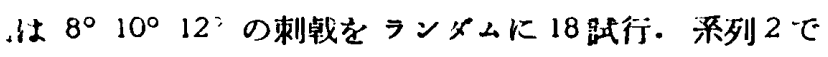

は $8^{\circ}, 10^{\circ}, 12^{\circ}$ の各々を $18^{\circ}$ の制战と対して与える.各 5 対, 計 30 試行.

以上の手つガきで行つた結果の川，主観的評点の上位 のものから 10 の数值をとり，それについて，Mと S.D を求めた。クロノスコープは系列の初めに 5 回琬テスト

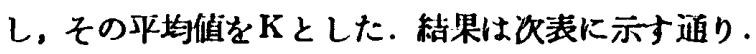

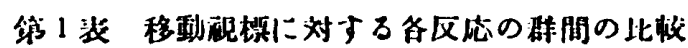
(茟位 ms)

\begin{tabular}{|c|c|c|c|c|c|c|c|c|c|}
\hline \multirow{2}{*}{\multicolumn{2}{|c|}{$\frac{5}{m}$}} & \multicolumn{2}{|c|}{1 etrastring } & \multicolumn{3}{|c|}{ 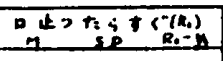 } & \multicolumn{3}{|c|}{ 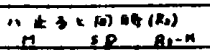 } \\
\hline & & 198 & 12 & 194 & 53 & 223 & 134 & 48 & 178 \\
\hline & 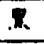 & 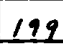 & 16 & 9 & 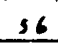 & 16 & 02 & 63 & 129 \\
\hline & 6 & 2 & 14 & 1098 & 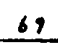 & 320 & r & 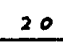 & 276 \\
\hline & I & 240 & 26 & 1012 & 58 & 36 & 728 & 2 & 2 \\
\hline & tp & 207 & 39 & 961 & 69 & 185 & 793 & 114 & 17 \\
\hline & 至 & 268 & 65 & 0,17 & 91 & 266 & 6.8 & 107 & -163 \\
\hline & + & 331 & 40 & 676 & 318 & -4 & 12 & 17 & 192 \\
\hline & E & 341 & 47 & 894 & 131 & 24 & 665 & 45 & -5 \\
\hline & $\pi$ & 394 & 39 & 746 & 187 & -24 & 760 & 80 & -10 \\
\hline
\end{tabular}

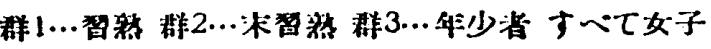
$\mathbf{M}$ は剌故が魂野に隹示されてから $\mathbf{R}_{1}, \mathbf{R}_{2}, \mathbf{R}_{3}$ まで

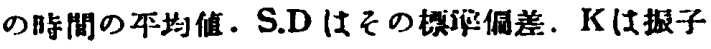
の $1 / 4$ 凩期に相当するクロシメーター值.

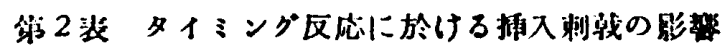
(羊位 $\mathrm{ms}$ )

\begin{tabular}{|c|c|c|c|c|c|c|c|c|}
\hline \multirow{2}{*}{\begin{tabular}{|l}
5 \\
3 \\
4
\end{tabular}} & \multicolumn{2}{|c|}{$M \quad V_{i p}, R_{1}-k$} & \multicolumn{2}{|c|}{$m \quad v_{i p_{1}} R_{1-k}$} & \multicolumn{3}{|c|}{$m \quad S_{10}^{S}, R_{1}-n$} & \multirow{2}{*}{ 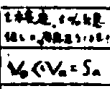 } \\
\hline & $1013 \quad 31$ & 242 & $1011 \quad 45$ & 302 & $105\}$ & 48 & & \\
\hline ? & 26 & E & & 2 & & & & \\
\hline to & & 2 & & 36 & & 4 & 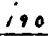 & \\
\hline$A_{0}$ & & 117 & & 1 & & 951 & 17 & \\
\hline & & 2 & 954 & 79 & 3 & +0 & 3 & \\
\hline$\approx$ & 76 & 70 & 73 & 66] & 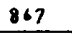 & 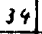 & 8 & \\
\hline & & & & & 191 & 106 & -7 & \\
\hline
\end{tabular}
$V_{u} \cdots$ 柔列 $198^{\circ}, 10^{\circ}, 12^{\circ}$ の混合
$V_{\mathrm{n}} \cdots$ 乐列 2 の
S..." の の対にした $18^{\circ}$

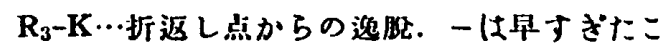 とをあらわす

III 結果 第一表に択ては，もし反応が理想的に行わ れたとすれば，イでは視剌钱による反応侍間に近く，ロ では $\mathrm{R}_{\mathrm{i}}-\mathrm{K}$ が当人の $\mathrm{R}_{1}$ に近く， 八では $\mathrm{R}_{\mathrm{3}}-\mathrm{K}$ がOK 近つくことが期得される。この規淮から三群を刘照すれ ば，イでは简單反心時間の一般的知見と一致してお゙り， ロでは群3の R-K が著しく小であり，S.D が大である. 群 1，2 間は大美ない，即ち年少者は巽常に早く区匛し， 反忘は不南一である.八では $\mathrm{R}_{3}-\mathrm{K}$ が群 2,3に比し群3 が卯つて大であり，しかもS.Dは小さい，即ち体育し たものは常に一定つ䜋をもつて渞つた反応をしたことに 
๙るる。第一表では $\mathrm{R}_{3}-\mathrm{K}$ を $\mathrm{V}_{\mathrm{o}}$ と $\mathrm{V}_{\mathrm{n}}$ について比較し， その恙は他の条件がー一定なれば，捅入刺钱 S、の影暂と 見る、枯果は概して言えば $\mathrm{V}_{\mathrm{n}}$ の力か大になり，そして

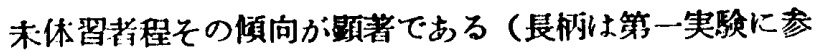
加）但しこ〉では $\mathrm{S}_{3}$ が逆に影㹕されることも表机てい るが，一応度外視した。

\section{平衡能に関する研究（第一報）}

東京学芸大学

大野 武治 ○関

1. 研究の目的

この研究は現在まで平畐能を調べる力法と見做され ている梌查泆と，之を多少修正した力法で，子供迸 の能力の発達過程を検討与る目的で実施したものであ ろ.

2. 研究の才j法

（1）検查内容 自発的飞均衡倩碍を起させる条仆を閉 眠と基底面の变化の 2 つして次の各検昰䡚目に何れか 一つを折込及类施した。

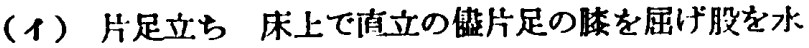

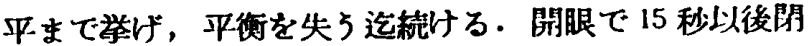

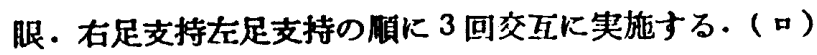
壮均台渡り台上の巾を $6 \mathrm{~cm} \sim 4 \mathrm{~cm}, 4 \mathrm{~cm} \sim 2 \mathrm{~cm}, 2 \mathrm{~cm}$ 〜 $1 \mathrm{~cm}$ の長さが夫々 $3.5 \mathrm{~m}$, 高さ $15 \mathrm{~cm}$ の平均台を一

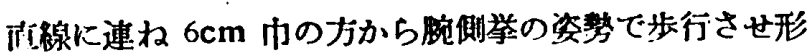

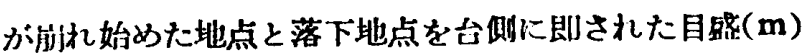
て垲み記録する. 3 回実施 (八) 足踏み 半径 $20 \mathrm{~cm}$ の门の川央に足型にかいてその川に立たせ，直立の䍡閉 服して股を水平まで挙け゚分間 120 歩の速さで足踏みさ せ，牌の何れかか门周上を踏を迄の回数を数える．3 回実施 (二) 闑眼步行 安全な法場に $20 \mathrm{~m}$ の白楾 $\mathrm{AB}$ を引き点に赤旅を立て，その点を酒つて楾 $\mathrm{AB}$ に直 交する線 BC, BD を左右に引 $10 \mathrm{~m}$ 婉とり更に $20 \mathrm{~m}$ の点を印しておく．B点から $1 \mathrm{~m}$ 置をに BC, BD に印 をつける.被䮖者をA点で旗に向つて立たせす向を見定 みさせた上眼かくしをし碷に向つて频かせ BC,BDを最 初人崉儿た所を $\mathrm{B}$ 点から右 (左) $\mathrm{xm}$ として記録 $20 \mathrm{~m}$ 以上の佩向は $20 \mathrm{~m}$ として記琭する. 各検查は前記值序 K3 回宛行い、崤服步行以外は裸足で実施.

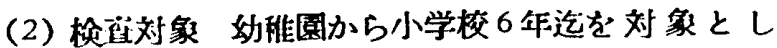
た。検萑。人員は别表 I II

（3）梌茫期刨了昭和 31 年 7 月 10月初旬

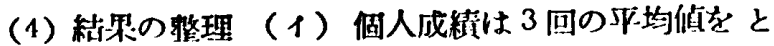

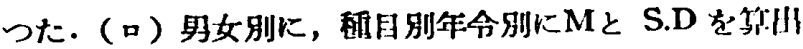

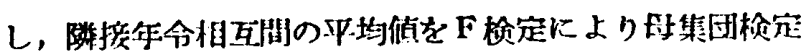

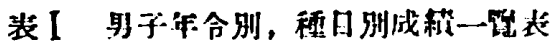

\begin{tabular}{|c|c|c|c|c|c|c|c|c|c|}
\hline & & 年少 & $\frac{5 k}{35 h}$ & $\frac{15}{571}$ & {$[25$} & \begin{tabular}{|ll}
3 & 9 \\
5 & 11
\end{tabular} & {$\left[\begin{array}{l}\frac{45}{53} \\
53\end{array}\right.$} & $\sqrt{5}$ & 6 \\
\hline & & 8 & 13757 & 1853 & $7 " 362$ & 23464 & $\frac{10}{n+0}$ & $\frac{284}{2848}$ & 379 \\
\hline & & 5.557 & 6.052 & 5.623 & 6.72 & 9041 & 9.96 & 10.87 & 19.38 \\
\hline & Mas & 25.83 & 28.17 & 30.27 & 37.23 & 55.6 & 65.17 & 12.7 & 109.4 \\
\hline & & 2.0 & 2.27 & 7.57 & 5.77 & 5.0 & 12.43 & 7.1 & 12.0 \\
\hline & & & & & & & & & \\
\hline & $M$ & $13^{\prime \prime} 724$ & $12^{\prime \prime}+23$ & 19112 & 20086 & $22^{\prime} 36$ & $28^{\prime \prime} 7$ & $26^{\prime \prime 6} 6$ & \\
\hline & - & 6.041 & 5.083 & 8.519 & 8.022 & 6.151 & 12.99 & 10.3 & 18.62 \\
\hline & $\ln x$ & 28.06 & 23.33 & 56.6 & 44.93 & 39.87 & 84.33 & 59.37 & 138.9 \\
\hline & aim & 2.2 & 3.73 & 6.33 & 8.63 & 9.9 & 6.30 & 4.9 & 12.13 \\
\hline & $M$ & 3.384 & $3.699_{m}$ & $3.774_{m}$ & $3776 \mathrm{~m}$ & 3.572 & 3.955 & $5.258 \mathrm{~m}$ & 5.67 \\
\hline & S.D & 1.284 & 1232 & 0.133 & 1.18 & 1.202 & 0.89 & 1.36 & 1.24 \\
\hline & aax & 623 & 6.83 & 6.6 & 7.13 & 6.7 & 587 & 8.10 & 8.5 \\
\hline & in & 0.83 & 1.13 & 1.53 & 1.2 & 1.3 & 2.17 & 2.37 & 3.43 \\
\hline & $D$ & 1.295 & 1.124 & 2.049 & 2.826 & 4.042 & 4004 & 2.959 & 3.422 \\
\hline & H & $4.679 \mathrm{~m}$ & 4.823, & $5.823 \mathrm{~m}$ & $6.602 \pi$ & $7621 \mathrm{~m}$ & 7.959 & $8.27 \%$ & $9.095 \mathrm{~m}$ \\
\hline & 5.0 & 1.424 & 1.325 & 1.453 & 1.807 & 1.599 & 1.36 & 1.38 & 1.46 \\
\hline & $a x$ & 7.5 & 7.4 & 10.17 & 10.5 & 10.5 & 10.2 & 10.5 & 10.5 \\
\hline & $\operatorname{Min}$ & 0.67 & 2.4 & 1.97 & 2.4 & 4.3 & 5.07 & 4.57 & 5.47 \\
\hline & & $2.53 \mathrm{~L}$ & 256 & 3556 & 15.072 & 102296 & 17.099 & D. & $3096 \%$ \\
\hline & 5.0 & 7.147 & 5.965 & 5.534 & 5.296 & 7.711 & 11.42 & 5.44 & 20.08 \\
\hline & $\mid a x$ & 47.33 & 33.33 & 30 & 30.33 & 45.67 & 79.69 & 35.0 & 144.33 \\
\hline & $\mathrm{lm}$ & 5.0 & 6.33 & 3.33 & 6.0 & 7.0 & 5.67 & 4.67 & 11.33 \\
\hline & $\bar{M}$ & $7.346 \mathrm{mon}$ & $7.142 \mathrm{~m}$ & $3.123 \mathrm{~m}$ & $2.826 \mathrm{~m}$ & 2.464 & 1.989 & 2.376 & 1.743 \\
\hline & S.D & 6.24 & 5.976 & 2433 & 1.708 & 1.507 & 1.36 & 2.03 & 0.254 \\
\hline & $\mathrm{Ma}$ & 1.16 & 0.6 & 0 & 0.17 & 0.73 & 0.07 & 0.07 & 0.33 \\
\hline & & 20. & & 9.4 & 6.17 & 7.7 & 5.43 & 9.90 & 4.03 \\
\hline
\end{tabular}

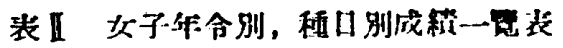

\begin{tabular}{|c|c|c|c|c|c|c|c|c|c|}
\hline \multirow{6}{*}{\multicolumn{2}{|c|}{\begin{tabular}{|l|l|} 
\\
\end{tabular}}} & & & & & & & & \\
\hline & & & & & & & & & \\
\hline & & & 228 & 50 & & & & 18.2 & \\
\hline & & & 50 & & & & & 1111.0 & \\
\hline & & 32 & 6.43 & 6.9 & 4.5 & & & & \\
\hline & & & & & & & & & \\
\hline & $M$ & $15 \% 4$ & 243 & 364 & 366 & 9335 & $x^{3} 335$ & 54 & \\
\hline & 50 & 0.215 & 94 & 975 & 7.545 & 10.529 & 7 & 20.12 & 2. \\
\hline & 3 & 3000 & .13 & 5.77 & 50.47 & 69.33 & 74.33 & 122.0 & 99. \\
\hline & & 26 & 7.33 & 7.73 & 5.4 & 13.87 & 11.43 & 14.33 & 12. \\
\hline & $\bar{M}$ & $3.125 \mathrm{~m}$ & [4.383 & $\bar{M} I_{m}$ & $82 \mathrm{~m}$ & 4.02 & $12 \mathrm{~m}$ & 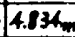 & \\
\hline & & 72 & $\overline{1.347}$ & 229 & 66 & 274 & 29 & 52 & \\
\hline & & 7.7 & 7.6 & 0 & & 7.43 & & & \\
\hline & & $\frac{1.0}{1.34 ?}$ & \begin{tabular}{|l|l|}
1.4 \\
0.5
\end{tabular} & $\frac{1.03}{1.679}$ & $\frac{1.5}{2.107}$ & $\begin{array}{l}1.3 \\
3.589\end{array}$ & $\frac{2.10}{3.014}$ & \begin{tabular}{|l|}
2.17 \\
2.760 \\
\end{tabular} & \\
\hline & & 13981 & $4.08 \mathrm{~m}$ & {$[5.394 \pi$} & & $\frac{9.30 \% \mathrm{~m}}{150}$ & 3 & 14 & \\
\hline & & 77 & 947 & 83 & 233 & 17 & 9.83 & 10.5 & \\
\hline & & 1.56 & 2.73 & 2.23 & & 5.13 & 3.57 & 4.3 & \\
\hline & & 592 & & & 1496 & 48 王 & 333 & 115.379 & \\
\hline & & 60 & $\frac{1}{5}$ & .07 & 486 & 917 & 28 & 7.32 & \\
\hline & & 31 & 53.33 & .33 & 28.0 & 63.0 & 60.69 & 52.33 & \\
\hline & & & 70 & & & 4.0 & .0 & .67 & \\
\hline & & & & & & & & & \\
\hline & & 6.634 & & & & 1.212 & 1.81 & 5 & \\
\hline & & 0.9 & 57 & 1.07 & 0.33 & 0.23 & 0.43 & 0.33 & \\
\hline & & 0.0 & & 119 & + & 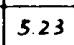 & 8.1 & 12.13 & 15 \\
\hline
\end{tabular}

